\title{
The economic impact of red palm weevil Rhynchophorus ferrugineus Olivier in Egypt
}

\author{
Mohamed Kamal Abbas \\ Plant Protection Research Institute, Egypt, email: Mohamed.kmal55@yahoo.com
}

\begin{abstract}
Abbas, M.K. 2019. The economic impact of red palm weevil Rhynchophorusf errugineus Olivier in Egypt. Arab Journal of Plant Protection, 37(2): 205-205.

The red palm weevil (RPW) Rhynchophorus ferrugineus (Olivier) (Coleoptera: Curculionidae) is a palm borer introduced to the Arab World, and was first recorded in 1992 in Egypt in date palm plantations of Sharkia and Ismailia Governorates. The infestation now covers all 26 governorates in Egypt, with infection rates from 2\% to 35\%. Date palm is considered of economic importance in Bahria and Siwa oases and Aswan with infestation rate exceeding 20\%, and the highest infestation rate was recorded in 2014 on more than 250,000 infested date palm trees. The most important control measures applied were pesticides spraying and injection, palm removal, prevention of spread through offshoots, agricultural extension and aggregation pheromone trapping in some areas. The cost of control operations in Sharkia and Ismailia Governorates were around 10 million Egyptian pounds (around 3 million USD) during the period from 1992 to 2000, which included the use of 160 tons of pesticides (more than 25 tons per year) as well as fuel, sprayers, and labor. The estimated total cost per year in Egypt was around 354 million Egyptian pounds (20 million USD) which include labor cost of periodic monitoring (2700 persons to investigate 6000 palm trees/person/month, with a cost 4.55 million USD per year), protective spraying during March and November (13.4 million USD), and quarantine operations, removal of highly infested palms and eradication with a total cost around 2-3 million USD, and funding was not always available which lead to increased damage. The estimated total loss since 1992 untill now is around 4 billion Egyptian pounds (400 million USD), taking into consideration the cost of replantation, removal of highly infested palms and control operations, in addition to the negative impact on 100 date factories due to reduction in the total amount of dates processed.
\end{abstract}

Keywords: Red palm weevil, removal, economic loss, quarantine.

\begin{tabular}{|c|}
\hline 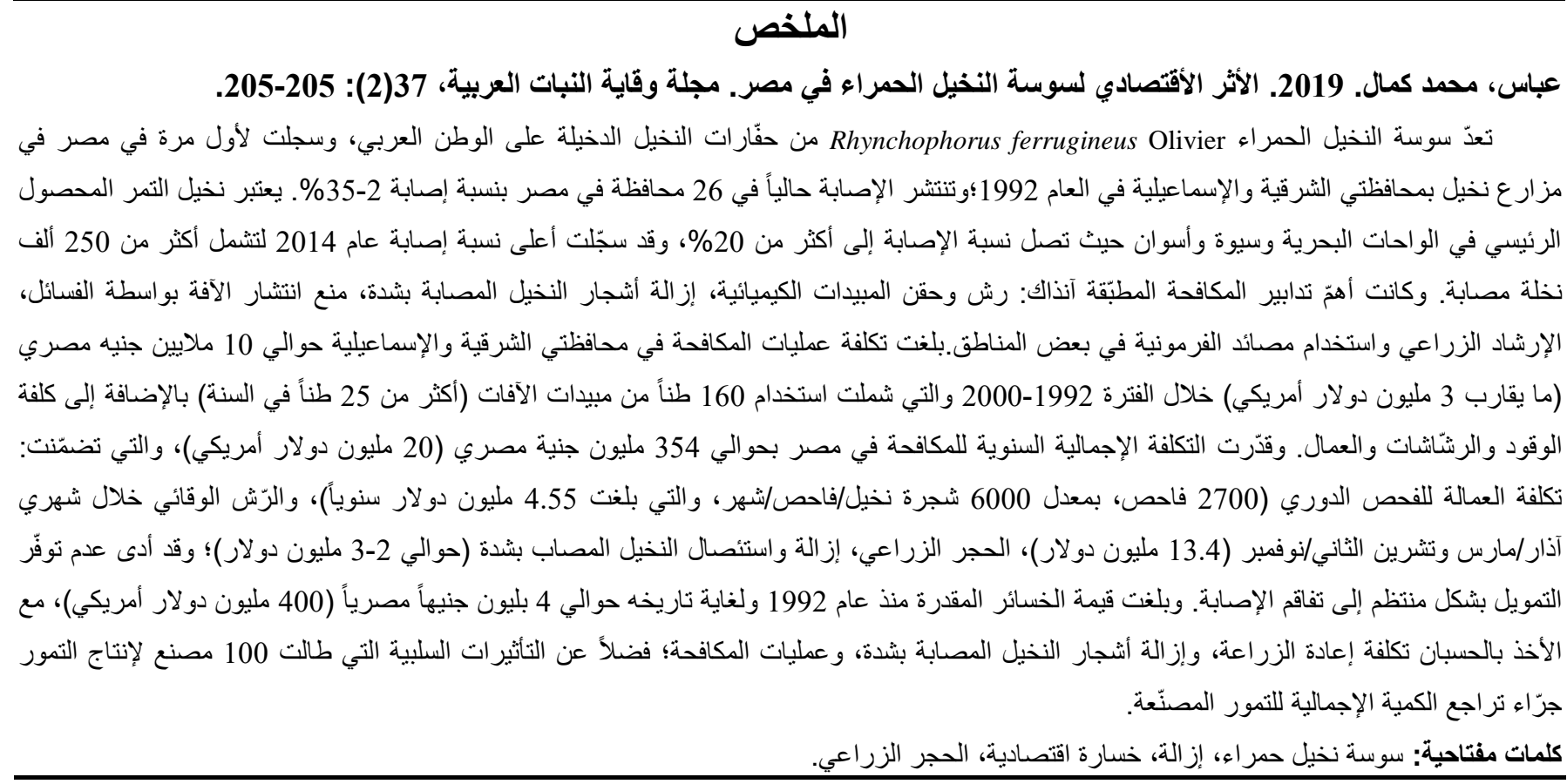 \\
\hline
\end{tabular}

http://dx.doi.org/10.22268/AJPP-037.2.205205

(C) 2019 Arab Society for Plant Protection الجمعية العربية لوقاية النبات

Arab J. Pl. Prot. Vol. 37, No. 2 (2019) 205 